\title{
La evaluación de la
} sociallización famililar: ESPA29

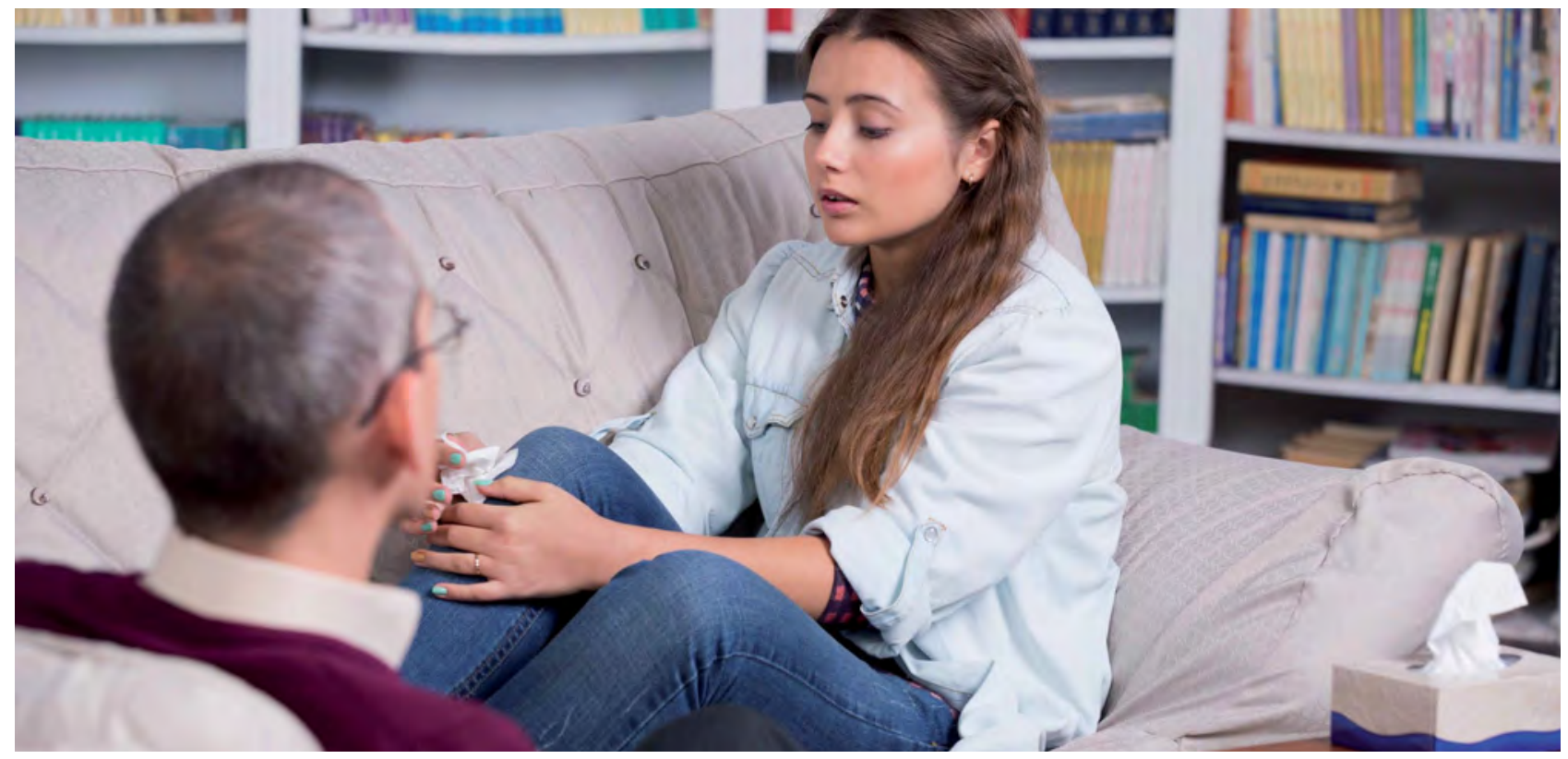

Tradicionalmente la socialización familiar se ha considerado un importante correlato del bienestar psicosocial de los hijos e hijas y un constructo teórico básico con el que entender conductas ajustadas y adaptadas dentro de la sociedad. La evaluación del proceso de socialización requiere una perspectiva teórica que conceptualice cómo pueden influir los padres en sus hijos. Sobre la base del clásico modelo bidimensional de socialización, con los ejes de aceptación/implicación y severidad/ imposición se definen cuatro tipos de actuación

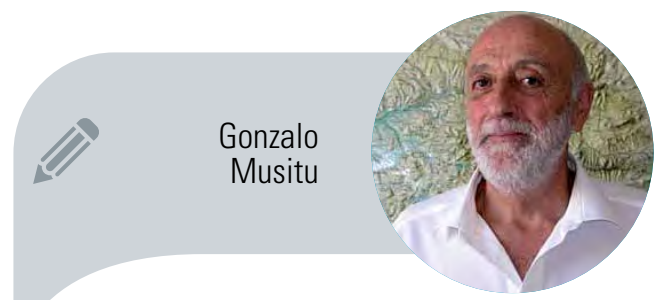

Departamento de Educación y Psicología Social, Universidad Pablo Olavide gmusoch@upo.es

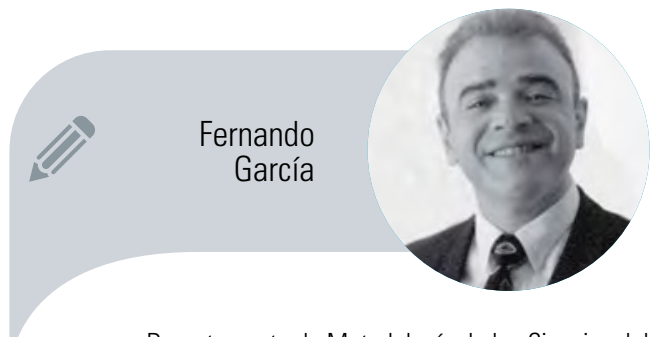

Departamento de Metodología de las Ciencias del Comportamiento, Universidad de Valencia fernando.garcia@uv.es parental: indulgente, autorizativo, negligente y autoritario. La escala ESPA29 es idónea para la evaluación de la socialización familiar. 
La socialización se define como el proceso mediante el cual las personas interiorizan los valores, creencias, normas y formas de conducta apropiados en la sociedad a la que pertenecemos. A través de ella aprendemos los códigos de conducta de una sociedad determinada, nos adaptamos a ellos y los cumplimos para el buen funcionamiento social. La meta final de este proceso es, por tanto, que la persona asuma como principiosguía de su conducta personal los objetivos socialmente valorados, es decir, que llegue a adoptar como propio un sistema de valores internamente coherente hasta conformar un filtro que le servirá para evaluar la aceptabilidad de su comportamiento. Naturalmente, los períodos de la infancia, la niñez y la adolescencia son fundamentales en este proceso y, en consecuencia, la familia se ha considerado un lugar especialmente privilegiado para la transmisión de valores y para el ajuste de los hijos.

A comienzos del siglo pasado John B. Watson (1928), prestigioso psicólogo estadounidense, advertía a los padres sobre lo superfluo de las muestras de afecto y cariño hacia los hijos y la necesidad de actuar severamente con ellos para imponer la educación y que los hijos aprendan las normas sociales. Durante décadas, el modelo bidimensional de socialización parental, con cuatro tipologías ha servido a la psicología de referente para explicar las posibles actuaciones de los padres en su tarea de educar a sus hijos. Los dos ejes evalúan si la actuación general de los padres es, por una parte, de aceptación/implicación y, por otra, de severidad/imposición. Cuando un padre actúa con aceptación/implicación y severidad/ imposición se denomina estilo de socialización autorizativo; si actúa con aceptación/implicación pero sin el componente de severidad/imposición, indulgente; si lo hace con severidad/imposición pero sin la aceptación/implicación, autoritario; y finalmente, si actúa sin aceptación/implicación y sin severidad/imposición, su estilo de socialización se denomina negligente (Musitu Y GARCía, 2001).
Figura 1. Modelo de socialización bidimensional y tipologías

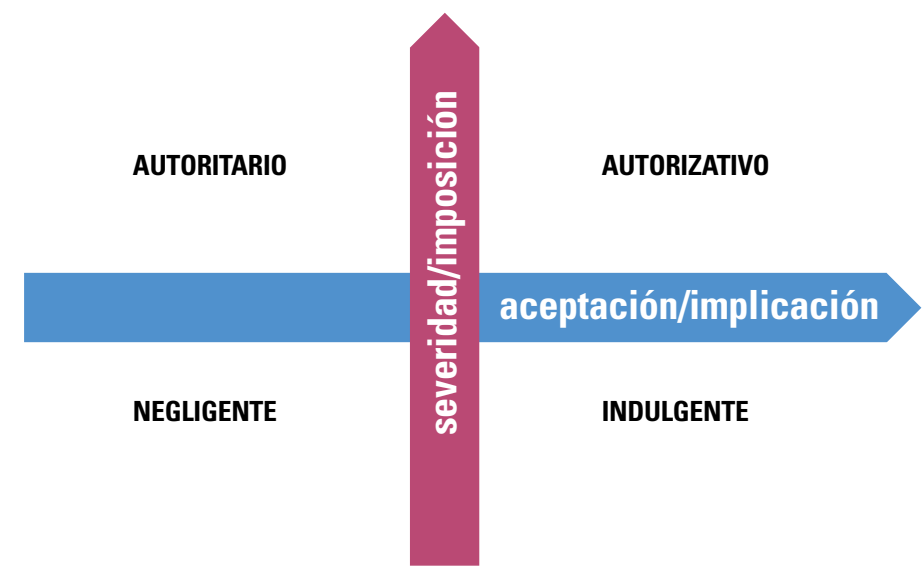

Figura 2. Sistema de Evaluación del ESPA29

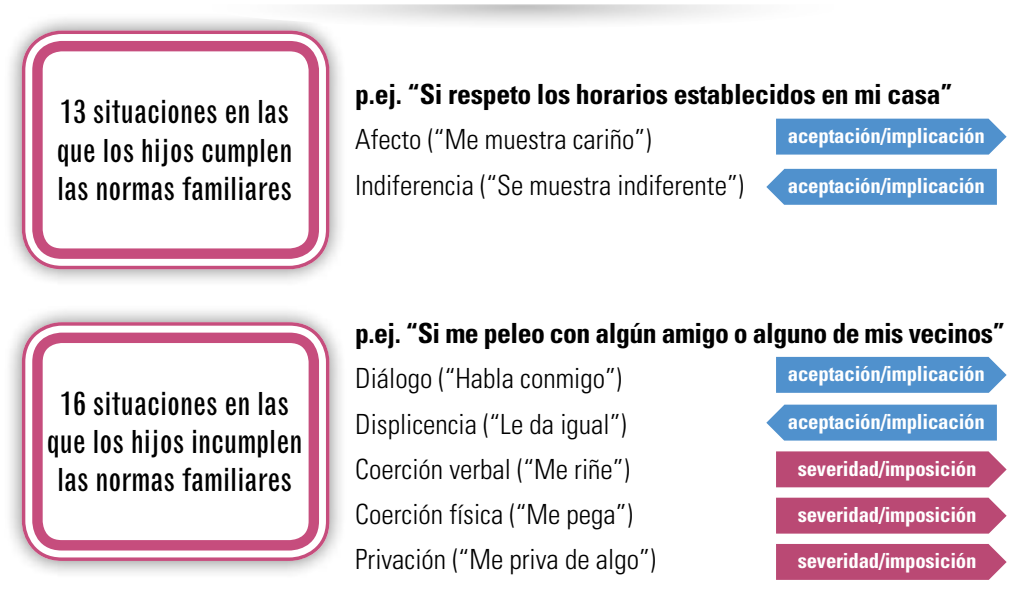

\section{La familia se ha considerado}

un lugar especialmente

$$
\begin{aligned}
& \text { privilegiado para la transmisión } \\
& \text { de valores y para el ajuste de } \\
& \text { hijos e hijas }
\end{aligned}
$$

Con el modelo bidimensional se pretende sintetizar actuaciones parentales generales y a largo plazo, lo que se denomina estilos parentales. Las actuaciones puntuales en un momento determinado se denominan prácticas parentales. Esta distinción entre prácticas y estilos parentales es muy importante a la hora de establecer correlatos entre las actuaciones de los padres a partir del modelo bidi- 


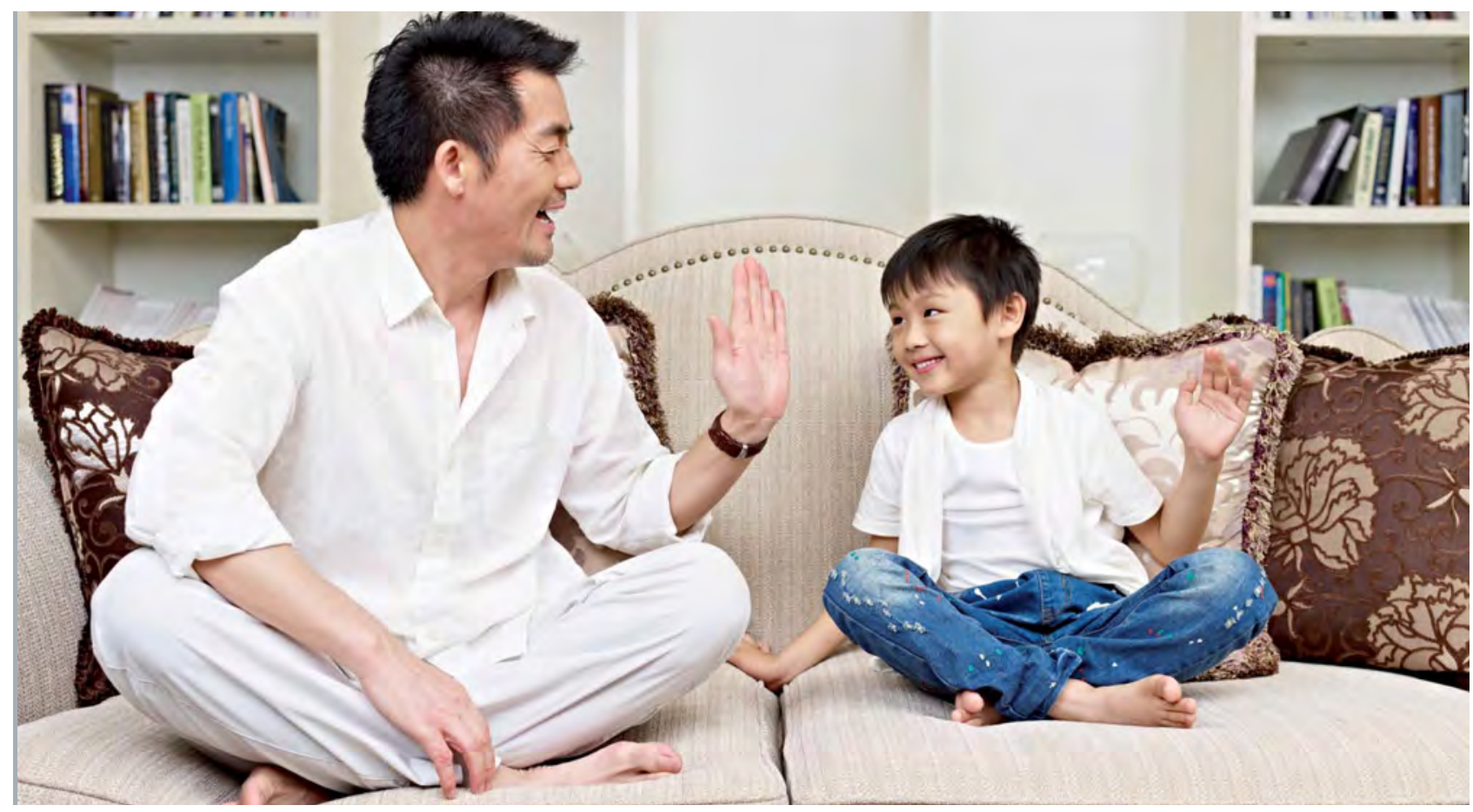

Figura 3. Representación del estilo parental con el ESPA29

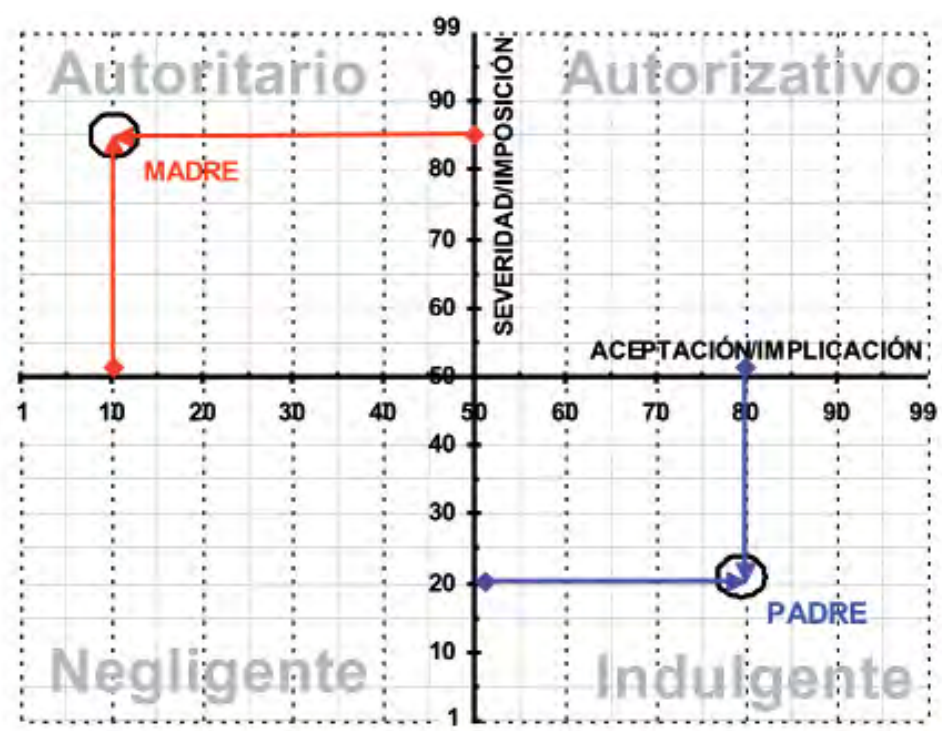

mensional y su trascendencia en el bienestar de los hijos. Si, por ejemplo, un niño actúa de manera inapropiada y se pelea con un amigo, ¿cómo debería actuar el padre? Analizando únicamente una situación aislada (práctica parental) es difícil y arriesgado establecer relaciones consistentes entre la actuación del padre y las consecuencias en la conducta del hijo, pero analizando el conjunto de actuacio- nes del padre es más fácil establecer relaciones consistentes entre la actuación y el bienestar a largo plazo de su hijo, entre otras razones porque para poder establecer un diálogo eficiente entre ambos se necesita mantener una relación de confianza (DARLINg y StEINBERg, 1993).

En numerosos estudios empíricos realizados fundamentalmente en EE. UU. con la mayoría blanca se ha concluido que los hijos de familias autorizativas obtenían los mejores resultados en todos los criterios de ajuste evaluados, y los peores en los adolescentes de familias negligentes. En una posición intermedia se encontraban los hijos de familias autoritarias e indulgentes. Sin embargo, en trabajos empíricos se ha observado que el contexto cultural y los diferentes antecedentes étnicos o raciales cuestionan la idea de que exista un único estilo parental óptimo en todas las culturas. Por ejemplo, estudios realizados con minorías étnicas de EE.UU. sugieren que el estilo parental autoritario es óptimo para adolescentes de procedencia asiática y de la minoría negra. Por otra parte, en investigaciones emergentes de diversos contextos culturales (sobre todo del sur de Europa y de América Latina donde se encuentra España) se apoya la idea de que el estilo autorizativo no siempre está asociado con los mejores resultados en los hijos, sugiriendo que el estilo parental indul- 


\section{El estilo parental indulgente, caracterizado por la aceplación/implicación pero sin severidad/imposición, se relaciona con un mejor ajuste psicosocial de hijos e hijas adolescentes}

gente, caracterizado por la aceptación/ implicación pero sin severidad/imposición, se relaciona con un mejor ajuste psicosocial de los adolescentes. Estas discrepancias en los resultados parecen revelar la influencia de la cultura en la relación entre la socialización parental y el ajuste psicosocial de los adolescentes.

En culturas colectivistas como las sociedades asiáticas y árabes, los niños perciben su self individual como parte del self familiar; en estas sociedades, la relación entre las generaciones de padres e hijos se espera que sea vertical y jerárquica, asumiéndose la severidad y la imposición como una responsabilidad parental; las prácticas autoritarias tienen un impacto positivo debido a que, en esos contextos, la disciplina parental estricta y la imposición

\section{ÂEORA DE DROFESORES}

El comportamiento de los padres y su estilo educativo tiene una incidencia insoslayable en el comportamiento de los hijos: es fundamental estar atentos al estilo educativo y prácticas parentales concretas que utilizamos, ya que muchos problemas de comportamiento del adolescente pueden solucionarse modificando algunos aspectos de nuestro estilo parental.

Durante la adolescencia es importante que en la familia se produzcan ciertos cambios en relación con las dimensiones de apoyo y control parental: los padres han de procurar estar, por una parte, atentos a las necesidades del adolescente para incrementar su responsabilidad y toma de decisiones en la familia mientras que, al mismo tiempo, han de mantener un alto nivel de cohesión y afecto en el entorno familiar. Es decir, el control disminuye mientras que el apoyo debe permanecer elevado.

En cuanto a las prácticas parentales concretas, los adolescentes muestran un desarrollo más adecuado cuando sus padres: (1) mantienen normas claras en relación con el comportamiento de sus hijos; (2) refuerzan las reglas y normas con sanciones que no son excesivamente duras; (3) proporcionan una disciplina consistente; (4) explican sus afirmaciones; (5) permiten la reciprocidad entre padres e hijo en las discusiones familiares; (6) se implican en la vida diaria del adolescente y lo animan a desarrollar sus habilidades y, (7) potencian la diferenciación permitiendo al adolescente desarrollar sus propias opiniones en un entorno cohesivo.

parental son percibidas como favorables para los hijos, y su ausencia se consideraría como una falta de dirección y supervisión. Por otra parte, en estudios realizados en España y Brasil se sugiere que en culturas colectivistas horizontales, como países de Sudamérica o del sur de Europa, el self se concibe como parte de un grupo mayor (la familia), con la salvedad de que este grupo se organiza sobre una base igualitaria, en lugar de una base jerárqui-

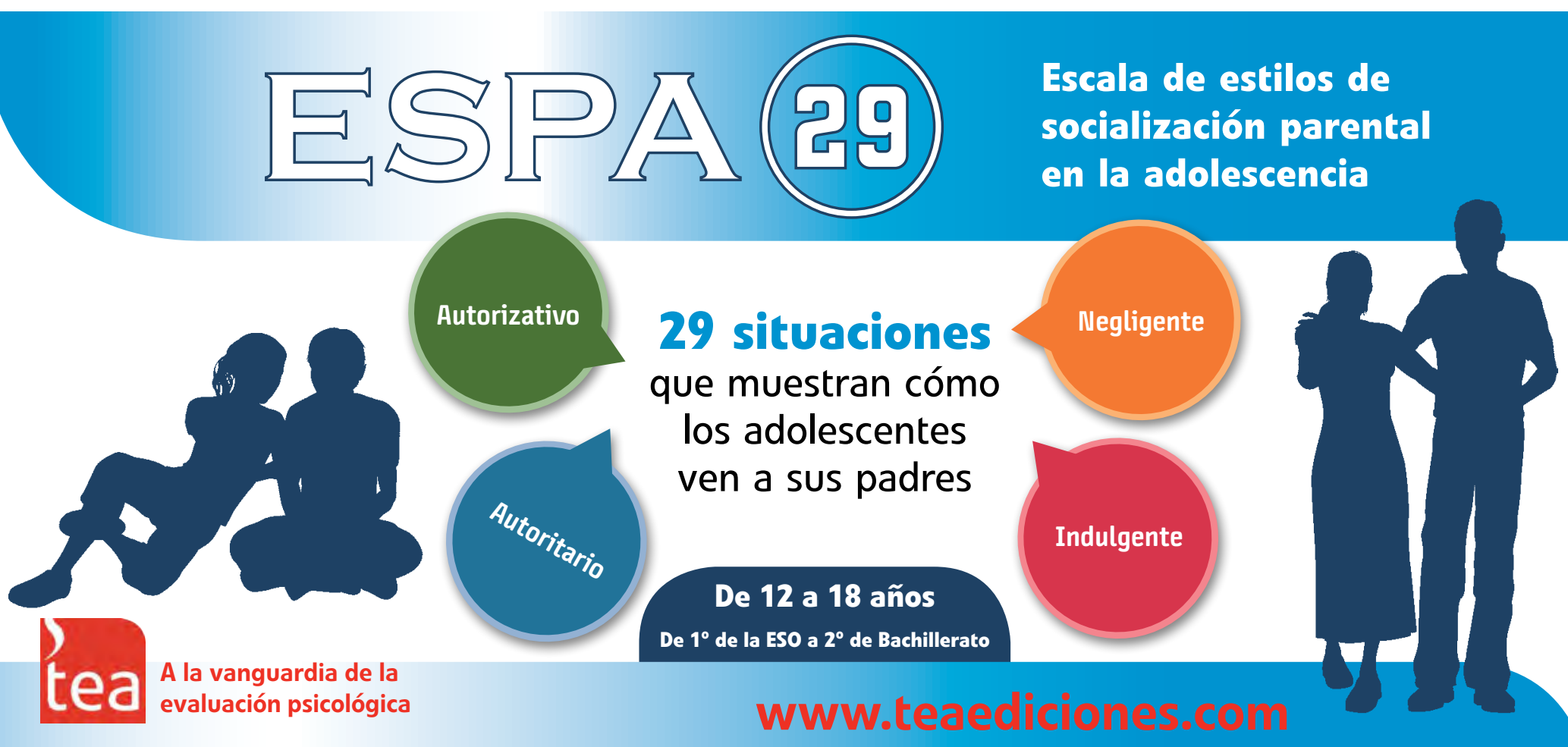




\section{ACTIVIDADES DE AULA}

Tanto en la familia como en cualquier otro espacio de convivencia, es necesario que se establezcan unas normas dentro de una organización clara. Para que esas normas y tipo de organización sean satisfactorias para todos, tienen que haber sido definidas desde el diálogo, el afecto, el respeto, la negociación y el consenso. De hecho, para que una persona se identifique y respete unas normas de convivencia, es necesario que participe activamente en su definición. Esto quiere decir que, contrariamente al estilo parental autoritario que ya conocemos, cuando los padres utilizan el estilo indulgente y autorizativo en el proceso de definición de normas y promueven la participación activa de los hijos, éstos consideran esas normas como propias y, por tanto, es mucho más probable que las respeten.

En este escenario de igualdad, afecto y compromiso, normas y organización nacen los acuerdos. Para llegar a dichos acuerdos, todos los miembros de la familia, padres e hijos, tienen que expresar sus motivos e intereses y aprender a escuchar los de los demás con respeto. Entre todos tienen que tomar decisiones y hacerse responsables de su cumplimiento. De este modo, la organización y las normas se convierten en una disciplina cooperativa donde todos comparten la responsabilidad del respeto a los acuerdos. Algo que es muy diferente al tipo de disciplina fundamentado en la obediencia de unos a otros (en este caso de hijos a padres), tal y como promueven los estilos parentales autoritarios.

\section{a) Responsabilidades en el hogar}

Paso 1

A continuación vamos a hacer un ejercicio de reflexión que nos permita hacer conscientes algunos procesos de nuestra familia relacionados con la organización y las normas de la casa. Empecemos por responder a estas preguntas:

\begin{tabular}{|l|l|}
\hline Preguntas & Respuestas \\
\hline 1) ¿Qué responsabilidades tenemos los padres? & 1) \\
\hline 2) ¿Quién definió estas responsabilidades de los padres? & 2) \\
\hline 3) ¿Qué responsabilidades tienen los hijos? & $3)$ \\
\hline 4) ¿Quién definió estas responsabilidades de los hijos? & 4) \\
\hline $\begin{array}{l}\text { 5) ¿Tanto unas como otras son útiles y eficaces para la organización en } \\
\text { la casa? }\end{array}$ & 5) \\
\hline
\end{tabular}

\section{Paso 2}

¿Qué ha contestado? Si las respuestas a las preguntas 2 y 4 son semejantes y tienen que ver con una definición realizada exclusivamente por los padres, y si la respuesta 5 es negativa, entonces se ha encendido la luz de alarma y será útil seguir trabajando este tema con las actividades B y $C$ que se proponen a continuación. Si la respuesta 5 es negativa, seguramente irá acompañada de una serie de consecuencias también negativas, como desorganización en la realización de tareas, falta de claridad o incoherencias en la distribución de tareas, discusiones frecuentes sobre quién hace tal o cual cosa, tensión, enfados, gritos, etc. Si reconoce alguna de estas situaciones, creemos que también reconocerá la utilidad de analizar, reflexionar y discutir explícitamente cómo es y cómo sería mejor la organización de la casa. Con las siguientes actividades le ayudaremos a mejorar esta organización.

\section{b) Revisión de normas y responsabilidades} Paso 1

Buena parte de la distribución de tareas y responsabilidades en las familias está influida por las costumbres sociales (por ejemplo, en función del sexo de padres e hijos). Sin embargo, cada familia tiene la posibilidad de definir cómo quiere vivir y cómo quiere organizar su convivencia. Para revisar estas pautas tradicionales de organización, en la tabla que encontrará a continuación haga una lista de algunas normas y responsabilidades que existen en su casa; al lado, indique si es una norma tradicional que se ha definido por costumbre, es decir, porque usted lo aprendió de su familia o si, por el contrario, es una norma propia definida específicamente en su familia actual; finalmente, escriba si esa norma produce satisfacción cuando se cumple 0 genera tensión y disgusto (imagínese la situación que produce el cumplimiento de cada norma y, como si se encendiese un semáforo, coloree con una luz verde 0 una luz roja la columna de la derecha). Añada tantas filas con normas como sea necesario.

\begin{tabular}{|l|l|l|}
\hline Norma & Origen & Color \\
\hline & & \\
\hline & & \\
\hline & & \\
\hline & & \\
\hline
\end{tabular}


Paso 2

Comparta el contenido de esta tabla con su pareja e hijos y anímeles a que asignen también un color a cada una de las normas de la lista. Vean en qué coinciden y en qué difieren. Si a una misma norma, sea propia o tradicional, uno de los miembros de la familia le asigna un color verde pero otro le asigna un color rojo, prevalecerá el color rojo y pasarán a hacer una lista de normas a revisar con todas aquellas normas que han sido señaladas, al menos una vez, con el color rojo. Con esta lista pasaremos a realizar la siguiente actividad.

\section{c) Redefinir normas y responsabilidades}

Paso 1

Examine los dos cuadros siguientes y las diferencias en su contenido

\section{Acuerdo $\triangleright$ Norma $\triangleright$ Responsabilidad $\triangleright$ Organización $\triangleright$ ¿Convivencia satisfactoria?}

Imposición $\triangleright$ Reglamento $\triangleright$ Obediencia $\triangleright$ Organización $\triangleright$ ¿Convivencia satisfactoria?

¿Cuál de los dos procesos de organización cree que conllevará una convivencia más satisfactoria, es decir, una convivencia donde todos se encuentren bien? Creemos que estará de acuerdo en que el primero, el que define las normas a partir de acuerdos, es el que más beneficios produce para una convivencia satisfactoria porque parte de la toma de decisiones conjunta donde todos se sienten partícipes. Esto favorece que cada uno se sienta dueño y responsable de esas normas y que, por lo tanto, su cumplimiento no produzca sentimientos negativos. Al contrario, en este contexto se está construyendo una organización en la familia que implica compromiso con los demás, se está definiendo una disciplina familiar indulgente.

Paso 2

A continuación le invitamos a que lea el siguiente cuadro de pistas para conseguir definir normas a partir de acuerdos:

\ La organización en la familia no es algo automático, es necesario dedicar un tiempo exclusivo para planificar y distribuir actividades.

\ La organización es una función que se debe desempeñar por todos los miembros de la familia. Todos participan en la definición de normas.

У El instrumento más efectivo para definir normas es el diálogo - disciplina indulgente y autorizativa - cualquiera que sea la edad de los hijos.

\ La utilización del diálogo tiene como objetivo llegar a acuerdos.

y Los acuerdos reflejan un proyecto común de convivencia y por tanto se traducen en la asunción de responsabilidades.

ע Las normas acordadas serán claras y ajustadas a las características de cada uno (edad, horario de trabajo/estudio, etc.).

Paso 3

A partir de las claves proporcionadas en el cuadro anterior, busquen un momento para que entre todos redefinan aquellas normas que han sido anteriormente calificadas con el color rojo. Para ello se puede utilizar una nueva lista:

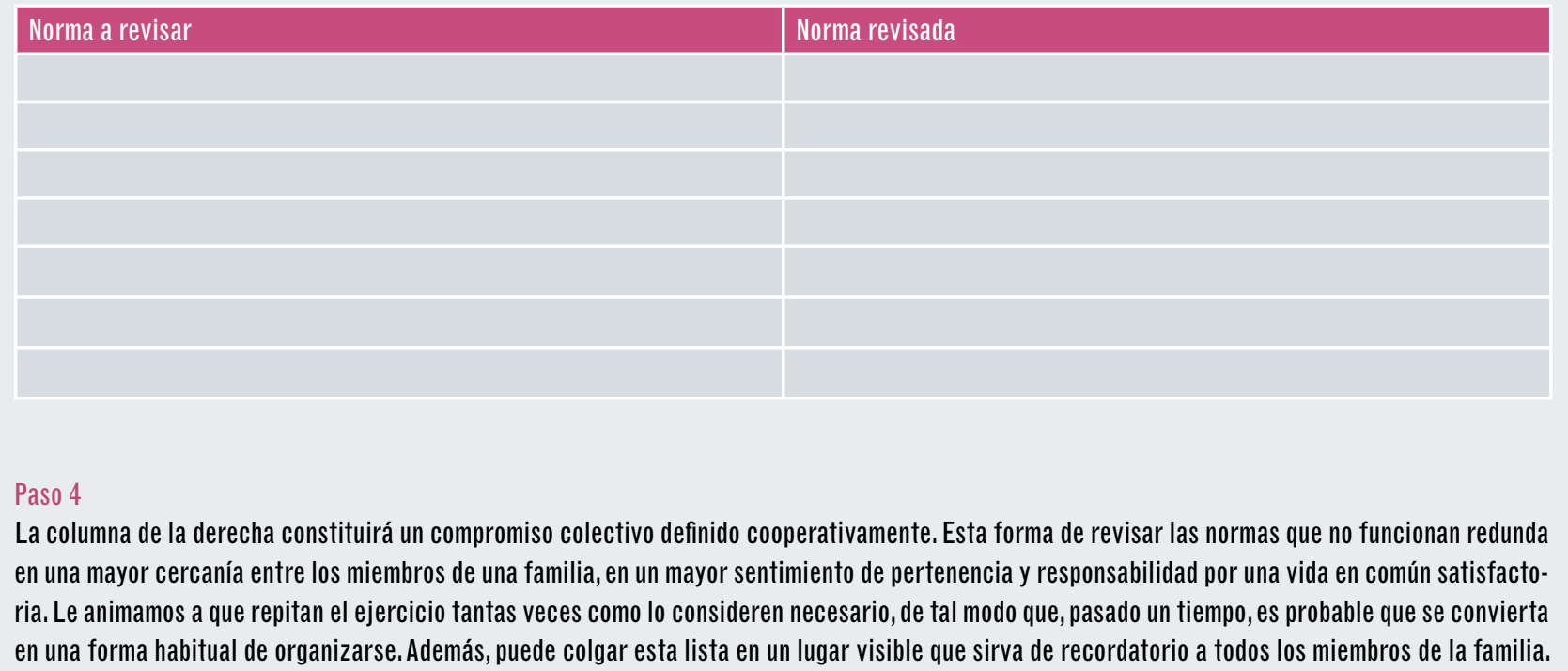


ca. En las culturas colectivistas horizontales se enfatizan las relaciones igualitarias y se presta más atención al cariño, la aceptación y la implicación como partes esenciales de la socialización de los hijos; además, en estas culturas, el uso de la severidad y las imposiciones en las prácticas de socialización parecen percibirse de forma negativa.

\section{La escala ESPA29 para evaluar la socialización familiar}

La escala de estilos de socialización parental en la adolescencia (ESPA29, de Musitu y GARcía, 2001) se compone de un total de 212 ítems con una escala de respuesta que oscila de 1 (nunca) a 4 (siempre). La escala evalúa la percepción que tienen los adolescentes sobre cómo actúan los padres en 29 situaciones representativas de la cultura occidental: 13 situaciones en las que los hijos cumplen las normas familiares (p.ej. "Si respeto los horarios establecidos en mi casa") y 16 en las que los hijos incumplen dichas normas (p.ej. "Si me peleo con algún amigo o alguno de mis vecinos").

Los adolescentes valoran la frecuencia con la que los padres les muestran afecto ("Me muestra cariño") e indiferencia ("Se muestra indiferente") en cada una de las 13 situaciones de cumplimiento de

\section{(ㄷ) DARR SABER MÁS}

Darling, N., \& Steinberg, L. (1993). Parenting style as context: An integrative model. Psychological Bulletin, 113, 487-496.

GARCIA, F. (2015). Parenting: Cultural influences and impact on childhood health and well-being. Hauppauge, NY: Nova Science Publishers, Inc.

Musitu, G., Estévez, E. y JimÉnez, T. (2010). Funcionamiento familiar, convivencia y ajuste en hijos adolescentes. Madrid: Cinca

Musitu, G. y García, J. F. (2001). Escala de Socialización Parental en la Adolescencia (ESPA29). Madrid:TEA Ediciones.

Musitu, G., \& García, J. F. (2004). Consecuencias de la socialización familiar en la cultura española. Psicothema, 16, 288-293.

Watson, J. B. (1928). Psychological care of infant and child. New York: W. W. Norton \& Co. las normas familiares; mientras que, para cada una de las 16 situaciones de desobediencia, los adolescentes indican la frecuencia con la que los padres responden mediante diálogo ("Habla conmigo"), displicencia ("Le da igual"), coerción verbal ("Me riñe"), coerción física ("Me pega") y privación ("Me priva de algo").

La puntuación de cada uno de los padres en aceptación/implicación se obtiene promediando las puntaciones en afecto, diálogo, indiferencia y displicencia (en las dos últimas se invirtieron las respuestas al relacionarse negativamente con la dimensión). La puntuación del padre en severidad/imposición se obtiene promediando las respuestas en coerción verbal, coerción física y privación. Ambos índices oscilan de 1 a 4 puntos; por lo que altas puntuaciones representan altos niveles de aceptación/implicación y severidad/imposición por parte del padre o la madre. A partir de estas puntuaciones se tipifica el estilo de socialización familiar como autorizativo, indulgente, autoritario o negligente.

Considerando la literatura especializada en la que se analiza la relación entre el estilo parental y el ajuste de los hijos en el entorno español, la intervención tiene que ir centrada en fomentar el estilo parental indulgente. Si uno de los padres se aleja de este estilo, la intervención se dirigiría en el sentido de incrementar el componente de aceptación/ implicación y reducir el de severidad/ imposición (GARcía 2015; Musitu y García, 2001, 2004) •

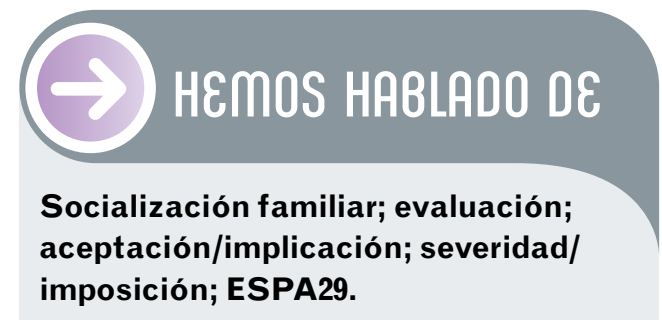

Este artículo fue solicitado por PADRES y MAESTROS en diciembre de 2015, revisado y aceptado en julio de 2016. 